\title{
De los objetos impelentes. ¿Quién iba a imaginarlos? Contribución a una fenomenología de la imaginación como configuración de escenas
}

On impelling objects. Who would have imagined them?

A contribution to a phenomenology of imagination as scenes configuration

\section{CÉSAR Moreno-MárqueZ}

Universidad de Sevilla

Facultad de Filosofía

Departamento de Metafísica y Corrientes Actuales de la Filosofía, Ética y Filosofía Política 41018 Sevilla (España)

cesmm@us.es

\begin{abstract}
The present article explores the phenomenological relevance of the imagination, taking as a guiding principle the "meaning-more" (intending beyond itself) of the horizon-intentionality. In particular, the article examines an extreme modality of this intentionality, the horizon of over-indetermination, which is decisive for understanding the phenomenological relevance of "impelling objects." These objects not only refer-to, but also allow a creative expansion of the horizon of phenomenality, with a view to the encounter between phenomenology and literary experience.
\end{abstract}

Keywords: Phenomenology, imagination, horizon-intentionality, Husserl.
Resumen: El presente artículo explora la relevancia fenomenológica de la imaginación tomando como hilo conductor el mentar-más-allá de la intencionalidad de horizonte, destacando una modalidad extrema de dicha intencionalidad, en la que se pone de relieve un horizonte de sobreindeterminación, decisivo para comprender el rendimiento fenomenológico de los objetos impelentes, que no simplemente remiten-a, permitiendo que se dilate creativamente el horizonte de fenomenalidad, con vistas al encuentro entre fenomenología y experiencia literaria.

Palabras clave: Fenomenología, imaginación, intencionalidad de horizonte, Husserl. 


\section{INTRODUCCIÓN}

unque un poco disimulado, uno de los pasajes decisivos de cara a pensar en profundidad el proyecto de la fenomenología trascendental se encuentra en el $\$ 35$ de La crisis, cuando se refería Husserl al trabajo del fenomenólogo en lo que denominaba su "tiempo profesional" y a lo que estaría más allá de ese tiempo, como su vida ordinaria. En lo esencial, Husserl venía a decir que a diferencia de un físico o un zapatero, cuando el fenomenólogo vuelve desde el tiempo profesional al ordinario, su vida cotidiana entretanto se ha transformado, hasta tal punto le habrá afectado existencialmente su compromiso "profesional" y la lucidez que haya podido alcanzar en él. A este respecto, Husserl hablaba de una "mutación personal" casi similar a la "conversión religiosa" . Pues bien, cabe imaginar que en esa vuelta, el fenomenólogo pudiera permitirse el lujo de leer a Proust, Machado o Gómez de la Serna (vid. infra) por placer, ciertamente, pero también en la medida en que pudieran ayudarle, en ese tiempo existencial, a comprender más de cerca la propia verdad de la defensa fenomenológica del mundo de la vida. Resulta imposible no imaginar la complacencia del fenomenólogo cuando leyese, por ejemplo, a esos autores encontrando en ellos un material extremadamente valioso, incluso fascinante, para su labor profesional en los vericuetos de la fenomenología como ciencia estricta entregada a su "campo de labranza" o aventurándose en "tierras incultas sin caminos"3 — lo que la convertiría (aparte de por otras razones) en una ciencia fascinante-.

1. E. Husserl, Die Krise der europäischen Wissenschaften und die transzendentale Phänomenologie, HU VI (Martinus Nijhoff, Den Haag, 1976) 140. Ed. cast., E. Husserl, La crisis de las ciencias europeas y la fenomenología trascendental (Crítica, Barcelona, 1991) 144.

2. E. HuSSERL, Ideen zu einer reinen Phänomenologie und phänomenologischen Philosophie I. Allgemeine Einfübrung in die reine Phänomenologie, Hu III,1 (Martinus Nijhoff, Den Haag, 1976) 224. Ed. cast. E. HusserL, Ideas relativas a una fenomenología pura y una filosofía fenomenológica (FCE/UNAM, México, 2013) 316. Citaremos en adelante Ideen I.

3. E. HusSERL, Nachwort a Ideen I (cit. supra) en su edición. inglesa, en Ideen zu einer reinen Phänomenologie und phänomenologischen Philosophie III. Die Phänomenologie und die Fundamente der Wissenschaften, Hu III, 1 (Martinus Nijhoff, Den Haag, 1971) 154 (ed. cast. Ideas I, 482). 
No sería necesario apelar al genio literario-fenomenológico de Sartre o a Bachelard ${ }^{4}$, o a alguna conocida declaración de MerleauPonty ${ }^{5}$. Bastaría recordar cómo reconocía Husserl, en Ideen I, que ante la precariedad de "donaciones originarias" se hacía necesario recurrir a la fantasía y fecundarla aprovechando

lo que nos ofrece la historia, en medida mayor aún el arte, y en particular la poesía, que son sin duda creaciones de la imaginación, pero que en lo que respecta a la originalidad de las reconfiguraciones, a la abundancia de los rasgos singulares, a la continuidad de la motivación, exceden con mucho a las operaciones de nuestra propia fantasía, y a la vez y gracias a la fuerza sugestiva de los medios de expresión artística se traducen con particular facilidad en fantasías perfectamente claras al aprehenderlas en la comprensión.

Así se puede decir realmente, si se ama el lenguaje paradójico, y decir con estricta verdad, con tal de que se entienda bien el equívoco sentido, que la "ficción" constituye el elemento vital de la fenomenología, como de toda ciencia eidética ${ }^{6}$.

Ya en 1907, en una carta a Hofmannsthal, Husserl reconocía la comunidad de intereses entre el fenomenólogo y el artista en torno a la indiferencia por aquello que la actitud natural considera como existente y real — si bien, añadía, al fenomenólogo no le guiaría tanto el disfrute estético cuanto esclarecer "el sentido que es inmanente a los fenómenos, no sobrepasando nunca ni en ninguna parte los meros

4. G. Bachelard, La poétique de l'espace (PUF, Paris, 1961) 1-21. Ed. cast. G. BACHElard, La poética del espacio (FCE, México, 1991) 7-32; G. BaChelarD, La poética de la ensoñación (FCE, México, 2002) especialmente 9-14.

5. M. Merleau-Ponty, Phénoménologie de la perception (Gallimard, Paris, 1945) XVI. Ed. cast. M. Merleau-PonTy, Fenomenología de la percepción (Península, Barcelona, 1975) 21: "La fenomenología es laboriosa como la obra de Balzac, la de Proust, la de Valéry o la de Cézanne: con el mismo género de atención y de asombro, con la misma exigencia de consciencia, con la misma voluntad de captar el sentido del mundo o de la historia en estado naciente".

6. E. HusSERL, Ideen I cit., 147-148 (ed. cast. Ideas I cit., 234-235). 
fenómenos $y$, por tanto, sin presuponer ni utilizar ninguna de las existencias trascendentes mentadas en ellos" -

Más allá de que el fenomenólogo persiga formulaciones conceptuales, lo cierto es que, en la medida en que pretendiera acercarse al mundo de la vida, podría y debería sentirse interpelado por los descubrimientos que de cara a la comprensión de la existencia humana llevase a cabo él mismo directamente, pero también con la asistencia de sus prójimos y de esos extraños "co-sujetos" del fenomenólogo que pudieran ser el artista o el autor literario a modo de egos experimentales ${ }^{8}$.

\section{INTENCIONALIDAD DE HORIZONTE, SOBRE-MENCIÓN Y ANÁLISIS INTENCIONAL}

Por seguir la indicación husserliana, nuestra aportación busca aproximarse a la elucidación conceptual de una cierta modalidad (muy conocida, en verdad, pero no por ello menos relevante) de la intencionalidad de horizonte en la que el "mentar más allá" imaginativamente parte de un objeto impelente 9 para, en el curso de un proceso en mayor o menor grado reflexivo, explorar el potencial de la imaginación con vistas al esclarecimiento de la existencia, y todo ello contando con la asistencia de la experiencia artístico-literaria.

7. E. HussERL, Brief an Hofmannsthal, Briefwechsel VII (Dordrecht, Kluwer, 1994) 133-36. Utilizo la trad. de C. Moreno en Fenomenología y filosofía existencial I (Síntesis, Madrid, 2000) 62-64.

8. M. KunderA, El arte de la novela (Tusquets, Barcelona, 1987) 40-44.

9. Por lo que se refiere a los que aquí denominaré "objetos impelentes", debo advertir que, hasta donde pueda saber o recordar, no me creo apoyarme en terminología específica husserliana alguna ni de otro autor — a expensas de que haya podido ser, en efecto, anteriormente utilizada (aunque yo lo desconozca)-. En el curso del artículo (vid. en especial nuestro epígrafe 3) se intentará aclarar que a diferencia de los objetos que simplemente remiten-a, los objetos "impelentes" permiten "saltar" a ámbitos que no están previstos o que no son predecibles según la estructura de indeterminación (ya en cierto modo determinada) de la intencionalidad de horizonte. Por ello, como se intentará mostrar, tales objetos "impelentes" exigen pensar a fondo no simplemente la estructura de indeterminación del horizonte intencional, sino un fondo de sobreindeterminación, o superindeterminación que sólo se deja acreditar en un ejercicio radical de imaginación (re) creadora. 
A tal efecto, los parágrafos consagrados en Meditaciones cartesianas a la intencionalidad de horizonte y al análisis intencional siguen resultando decisivos para entrever un terreno predilecto para la presentificación imaginante ${ }^{10}$. Decía allí Husserl que la multiplicidad propia de la intencionalidad es tal que, respecto a la vida de la conciencia,

toda actualidad implica sus potencialidades, las cuales no son posibilidades vacías, sino más bien posibilidades intencionalmente predelineadas respecto de su contenido en la misma vivencia actual correspondiente, y además provistas del carácter de posibilidades que han de ser realizadas por el yo. (...) Toda vivencia tiene un horizonte que cambia de acuerdo con la modificación de su conexión con la conciencia y con la modificación de las fases de su propio fluir ${ }^{11}$.

Más adelante, sostenía Husserl que el fenomenólogo debe dejarse guiar por el conocimiento de que

todo cogito, en cuanto conciencia, es sin duda, en el más amplio sentido, mención de lo mentado en él, pero que esto mentado es en todo momento más (mentado con un plus) que lo que en cada momento se halla como mentado explícitamente. En nuestro ejemplo, cada fase de la percepción era mero lado del objeto en cuanto mentado perceptivamente. Este mentar más allá de sí mismo (über-sich-binaus-meinen) que yace en toda con-

10. Consultar M. M. SARAIVA, L'imagination selon Husserl (Nijhoff, La Haye, 1970). Y sin duda, para ahondar en las problemáticas aquí sólo insinuadas, E. HusSERL, Phantasie, Bildbewußtsein, Erinnerung (1898-1925), Husserliana XXIII (Nijhoff, Den Haag, 1980).

11. E. Husserl, Cartesianische Meditationen und Pariser Vorträge, Hu I (Martinus Nijhoff, Den Haag, 1973) 81-82. 2 Ed. cast. E. HusserL, Meditaciones cartesianas (Tecnos, Madrid, 1986) 60-61. Sobre los horizontes interno y externo vid. E. HusserL, Erfahrung und Urteil. Untersuchungen zur Genealogie der Logik (Felix Meiner, Hamburg, 1985) 26-36. Ed. cast. E. HusSERL, Experiencia y juicio (UNAM, México, 1980) 32-41. En general, Experiencia y juicio rebosa de sugerencias, estímulos y claves para la investigación abordada aquí. 
ciencia tiene que ser considerado como un momento esencial de ella. Pero que se llame y tenga que llamarse un plus de la mención (Mebrmeinung) de la conciencia, tan sólo lo muestra la evidencia de la posible elucidación y a la postre el descubrimiento intuitivo, en forma de un efectivo y posible progreso del percibir o de un posible recuerdo, en cuanto yo puedo efectuarlos a partir de mí1 ${ }^{12}$.

A partir de aquí surgiría una tarea decisiva, en la medida en que el fenomenólogo no hubiera de entregarse ingenuamente al objeto, centrando la atención tan sólo en él y propiciando, de este modo, que se mantuviese en el anonimato la intencionalidad operante en sus multiplicidades y objetos intencionales constituidos unitariamente en ellas ${ }^{13}$. Husserl incluso pensaba que dicha conciencia no sería la de un mero e inmediato ego cogito sino, sobre todo, "la vida cogitativa anónima" que debería ser descubierta tanto en los "determinados procesos sintéticos de los múltiples modos de la conciencia” como, y no es baladí destacarlo, en

los modos aún más distantes del comportamiento del yo que hacen comprensible el ser-simplemente-mentado-para-el-yo de lo objetivo, tanto intuitivo como no intuitivo; o hacen comprensible cómo la conciencia en sí misma, en virtud de su correspondiente estructura intencional, hace necesario que llegue a ser consciente en ella semejante objeto que es y que es de tal manera, y que el mismo pueda presentarse como tal sentido ${ }^{14}$.

Husserl estaba especialmente motivado por la unidad del objeto $0^{15}$, que como cogitatum nunca se da acabadamente, poseyendo "aun en su indeterminación (...) una estructura de determinación"16. En este sentido, Husserl oscilaba con frecuencia entre destacar el reconocimiento de

12. E. Husserl, Cartesianische Meditationen cit., 84 (ed. cast. 63-64).

13. Ibidem, 84 (ed. cast. 64).

14. Ibidem, 84-85 (ed. cast. 64-65).

15. Ibidem, 87-89 (ed. cast. 67-71).

16. Ibidem, 83 (ed. cast. 62). 
la determinación, por una parte, y subrayar la importancia de la indeterminación "siempre con nuevos horizontes de apertura"17, por otra.

Pues bien, en el juego entre determinación e indeterminación horizónticas encontraría su relevancia, asimismo, el horizonte de variaciones eidéticas imaginarias del objeto ${ }^{18}$, en la medida en que "todo factum puede pensarse como mero ejemplo de una posibilidad pura"19. En tanto el "esto" es ejemplo, su horizonte lo enlaza eidéticamente con todos los "estos" que compartan el mismo eidos. En el horizonte de esta magdalena puede comparecer aquella otra magdalena del recuerdo... Tan poderoso es el vínculo eidético (lo que suele pasar desapercibido), que el encaminamiento eidético puede pasar de ser meramente relacionante entre esto y aquello, más o menos próximos en una secuencia eidética "típica", a remitir (progresiva o bruscamente) a lo más lejano intraeidético, potenciando a la imaginación o poniéndola en "ebullición" ${ }^{20}$. Por supuesto, si en lugar de un esto fáctico-perceptible, la intencionalidad de horizonte hubiera de vérselas con una mera mención de esto o aquello (por ejemplo, si simplemente digo "olmo"), las expectativas estarían ya eidéticamente orientadas tanto hacia el olmo más empíricamente próximo/familiar como - y eso sería muy relevante- hacia el más distante/diferente concebible. Se trata, sin duda, de una situación fenomenológico-trascendental-eidética decisiva en el orden del lenguaje, en ausencia de lo percibido ("supongamos que miramos con agrado en un jardín un manzano en flor" 21 ). Las idas y venidas desde el ejemplo al eidos, y vuelta, serían constantes. Precisamente, la imaginación/fantasía es decisiva tanto más cuanto más lejos nos "envíe", es decir, en la medida en que se pudiera, con su ayuda, superar ejemplos triviales o rutinarios. De este modo se comprende que, en su multiplicidad infinita (aunque determinada), las variaciones eidéticas

17. Ibidem.

18. E. HusserL, Erfabrung und Urteil cit., 410-436 (ed. cast. 376-399).

19. E. Husserl, Cartesianische Meditationen cit., 105 (ed. cast. 95).

20. Cfr. C. Moreno, Eidos y periferia. Número monográfico: "Recerca. Revista de Pensament i analìsi" 12 (2012) 23-51.

21. E. HusserL, Ideen I cit., 203 (ed. cast. 295). Cabe imaginar como una radicalización de este "supongamos" (angenommen) el "míralo allí..." de O. PAZ, El mono gramático (Seix Barral, Barcelona, 1988) 52. 
dependan del poder de imaginar en la medida en que la conciencia no esté obligada a simplemente ver ni a recopilaciones de "estos" percibidos o perceptibles en "proximidad" típica.

En el fondo, el horizonte abre o el horizonte se concentra en torno $a . .$. En este sentido, tendría razón Lévinas al sostener que el análisis intencional se orienta a la búsqueda de lo concreto, pero no ya ni sólo porque dicho análisis implique un desbordamiento hacia el horizonte del que viven las donaciones concretas del objeto ${ }^{22}$, sino también porque el horizonte de lo dado da juego a sus propias variaciones eidéticas en dirección al eidos y, aparte de ello —éste es propiamente nuestro tema-, acredita la oportunidad de configurar "escenas" posibles que sin ser aún propiamente "mundo" en la plenitud y complejidad de su entramado, acercan a las cosas al mundo-de-la-vida (sin quedar presas de un mundo fáctico) y - lo que es decisivo-incitan a nuestras propias nóesis a/en concreciones de muy significativa relevancia existencial. El objeto se torna guía, motivo y excusa, sin duda, pero no simplemente de lo co-dado en él en tanto mera unidad objetiva, ni de meras variaciones eidéticas de sí mismo tomado como ejemplo, sino especialmente de escenas que pueden ser abiertas o encontradas, o tal vez recreadas, sobre todo, a partir de la estructura de sobreindeterminación de su horizonte. Es preciso señalar esta sobreindeterminación porque, de otro modo, el horizonte se tornaría "constrictor" de la intencionalidad ${ }^{23}$, sin que la mera indeterminación pudiese evitarlo a fondo. Aquí no se trata de los fenómenos saturados en el sentido específico de Marion, pero sí de una suerte de "saturación" en la medida en que la imaginación pueda atender a objetos impelentes que conduzcan sobreindeterminadamente hacia zonas muy distantes de ellos, de modo que se los pueda asumir en horizontes de sentido (no importa si de procedencia o de destino) a modo de variaciones escénicas imaginarias de dichos objetos.

22. E. LÉVINAS, Totalité et infini. Essai sur l'extériorité (Martinus Nijhoff, Den Haag, 1971) XVI-XVII. Ed. cast. E. LÉVINAS, Totalidad e infinito. Ensayo sobre la exterioridad (Sígueme, Salamanca, 1977) 54.

23. J.-L. MARIOn, Étant-donne. Essai d'une phénoménologie de la donation (PUF, Paris, 1997), 259-262. Ed. cast. J. L. MARION, Siendo dado. Ensayo para una fenomenología de la donación (Síntesis, Madrid, 2008) 306-309 (especialmente). 


\section{APERTURA DEL HORIZONTE, IMPELENCIA Y VARIACIÓN ESCÉNICA COMO EUFORIA DE LA IMAGINACIÓN}

Cualquier inspección de nuestros actos intencionales constatará la presencia, en nuestra vida de conciencia, de objetos-relación que son además remisionales ${ }^{24}$, pero no meramente en el sentido de que remitan a su totalidad respeccional precomprendida y pre-"visible", o simplemente susciten o motiven tales o cuales afectos (por ejemplo, los zapatos del niño-bebé cuando recuerdan a su padre la infancia de su hijo), sino que impelen o impulsan imaginativamente a "otra parte", transportan lejos del propio objeto, de un modo que pueda resultar muy imprevisto, habida cuenta de lo que la estructura típica de determinación-indeterminación del horizonte permitiría augurar. Podríamos llamarlos impelentes, reconociéndoselos en que casi siempre resultan ser euforizantes para las potencialidades de la Mebrmeinung (sobre-mención) que lleva a cabo la imaginación sobre la base, en esos objetos, de su horizonte no sólo de indeterminación sino, como hemos dicho antes, de sobreindeterminación. De este modo, la intencionalidad sería "lanzada", más allá del propio objeto, hacia ámbitos muy potencialmente indeterminados que no tendrían por qué guardar una relación de conformidad-anticipable con el objeto mismo sino, por ejemplo, impeliendo hacia la propia vida de conciencia, pero no en tanto ésta, en su típico cometido intencional, se dirige al objeto en cuanto tal, sino en tanto éste permite acceder a una "zona" de la vida de conciencia que se siente eufóricamente impelida más allá, a una zona de libre imaginación, ciertamente, en muchas ocasiones, al mismo tiempo motivada por el objeto, pero más allá de él, a través de nóesis imprevistas, por ejemplo, para cualquiera que no fuese su protagonista ${ }^{25}$. Hasta tal punto podrían conducir más allá, que en ocasiones podría presentirse que fuesen impelentes sin que, sin embargo, se pudiera determinar con preci-

24. M. Heidegger, Sein und Zeit, GA 2 (Klostermann, Frankfurt, 1977) 101-119. Ed. cast. M. HEIDEgGER, Ser y tiempo (Trotta, Madrid, 2016) 94-110.

25. Y, por tanto, más allá de la congruencia en el sistema de significatividades que permite la reciprocidad de perspectivas. A. SCHÜTZ, El problema de la realidad social (Amorrortu, Buenos Aires, 1974) 42-43, 282-283. 
sión hacia-qué. El objeto impelente hace de mediador, pero no de sí mismo ni de su horizonte externo, ni de su eidos, ni de meras remisiones más o menos típicas, intersubjetivizables, sino más allá... Si en buena medida ya la imaginación labora en la intencionalidad de horizonte, en este caso se ve potenciada al extremo, eufóricamente, pues se desenvuelve en — por decirlo sartreanamente- una "nada" cuya base sólo podría ser, in extremis, la propia vida de conciencia en su complejidad, vida de conciencia que, a su vez, se vería potenciada, en la medida en que "cuando se propone una conciencia, hay que proponerla como pudiendo imaginar siempre"26.

Los objetos impelentes acreditarían a fortiori, de este modo, que el horizonte de sobreindeterminación resulta ser, más que el de mera indeterminación, decisivo para la imaginación, destacándose, de este modo, que lo que está en cuestión es la apertura radical del horizonte enlazada intimamente al potencial imaginante y/o fantaseador del Yo-puedo...

Constituye una posibilidad decisiva para la imaginación, tal como puede desplegarse en una intencionalidad de horizonte, no sólo anticipar lo co-dado indeterminadamente de tal o cual objeto, o explorar sus variaciones posibles en una re(con)ducción eidética, sino también lo que podríamos considerar la posibilidad de configurarle o acogerlo en escenas de un eficaz y en muchos casos muy elevado rendimiento imaginativo-existencial. Como impelente, un objeto puede ser acogido en escenas cuando la imaginación lo "enmarca" fuera-de los entornos (todos respeccionales) en que se deja o se habría

26. J.-P. SARTRE, Lo imaginario. Psicología fenomenológica de la imaginación (Losada, Buenos Aires, 1964) 230: “¿La función de imaginar es una especificación contingente y metafísica de la esencia 'conciencia' o por el contrario tiene que ser descrita como una estructura constitutiva de esta esencia? Dicho de otra manera: ¿se puede concebir una conciencia que no imagine nunca y que esté totalmente absorbida en sus intuiciones de lo real —en este caso, la posibilidad de imaginar, que aparece como una cualidad entre otras de nuestras conciencias, sería un enriquecimiento contingente-, o, en cuanto se propone una conciencia, hay que proponerla como pudiendo imaginar siempre?”. 
podido "percibir" usual o típicamente ${ }^{27}$. Trátese, por ejemplo, de una "ventana entreabierta". Da lo mismo si viéndola o imaginándola, podríamos acercarnos a ella, inspeccionarla, o tomarla como ejemplo para emprender un recorrido de variaciones eidéticas con vistas a alcanzar el eidos "ventana", pero también podríamos, por gracia de la imaginación, acogerla — cuando ella nos cogiese a nosotros "por sorpresa", si se me permite decirlo así- como un objeto impelente en una escena, o incluso ponerla a la luz de un argumento que ya ninguna relación tuviese con ella.

Un objeto, en efecto, puede ser acogido-en-escenas suscitadas bien por su propia condición eidética inserta en mundos posibles diversos, bien bajo la eficaz motivación de noésis subjetivo-afectivas que ubiquen imaginativamente al objeto en escenas diversas, o en una escena concreta muy motivada, en la(s) que la imaginación ya no se orientase meramente al objeto, tomado como excusa, ni siquiera hacia su mero mundo de procedencia, sino a la propia nóesis que lo imagina o, en casos excelentes, a una posibilidad simbólica ${ }^{28}$. La nóesis no sería ante todo objetivadora, sino motivante, acogedora y creativa. Y ya no sería la "cosa" la que como mera unidad objetiva dejaría entreabierta una multitud de horizontes escénicos en los que podría ser liberada de su pasado, al tiempo que entregada a su eidos, versátil y mundanizado, sino que sería la propia nóesis la que entreabriese y sugiriera... pero — esto es importante- no a simple título

27. Aquí no podría ocuparme de las extrañas posibilidades horizónticas surreales del objeto, en las que éste acoge imaginariamente lo que no cabría esperar de él acorde a las rutinas de la estructura de determinación de nuestros horizontes objetivos internos o externos. En virtud de aquellas posibilidades surgen unidades objetivas sin duda anómalas, pero poderosamente sugerentes e impelentes, gracias a un Ich kann de "máximo rendimiento" — al que se vincula el imaginario mitopoiético muy amplia y profundamente- - Sin duda, la actitud natural, con cuyas tendencias ingenuo-amnésicas se muestra tan crítica la fenomenología trascendental, hace sentir su peso en ésta en la medida en que el proyecto filosófico de la fenomenología le reconoce sobrado (incluso excesivo) derecho y relevancia de cara a la hechura cuerda realista, racional, típica, familiar y pragmática del "mundo". Tampoco puede caber duda, por lo demás, de que una posibilidad tan antigua del logos poético como es la metáfora también se nutre de impelencias que "trastornan" a la actitud natural.

28. M. BlanCHOT, Le langage de la fiction, en La part du feu (Gallimard, Paris, 1949) 83-84. Ed. cast. M. BLANCHOT, El lenguaje de la ficción, en La parte del fuego (Arena Libros, Madrid, 2007) 73-82. 
veritativo-epistémico, o incluso hermenéutico, sino sobre todo afectivo-simbólico-existencial, según motivaciones del narrador a modo de guía o tutor (en el caso de la experiencia literaria).

Respecto a la posibilidad de proponer la configuración de escenas, lo decisivo sería la dilatación fenomenológica que tiene lugar en la intencionalidad de horizonte y en su potencial de sobremenciones de acuerdo a las motivaciones provocadas por objetos impelentes. La guía para esta propuesta nos la sugirió hace tiempo Heidegger cuando en El origen de la obra de arte dice "Un par de botas de campesino y nada más, y sin embargo" 29 ... Lo decisivo es ese Sin embargo que se enfrenta a la mera y casi obsoleta identidad (botas de campesino) y, sobre todo, al Nada más que..., como si el desafío fenomenológico-hermenéutico consistiese en abrir/ubicar ese polo idéntico del objeto-sustrato "botas" remitiéndolo a un mundo (Heidegger) o relanzándolo a una vida (Proust, Machado). El a priori de correlación se dejaría entonces exceder respecto a sus hábitos, rutinas y cotidianeidad, en la medida en que la imaginación le permitiera no quedar preso del mero mundo percibido/recordado (fáctico).

\section{4. ¿QUIÉN IBA A IMAGINARLOS? TRES EFEMPLOS}

Antes de proseguir con los ejemplos que quisiera aducir, desearía recordar brevemente dos recursos que me han resultado muy valiosos de cara a la temática que me ocupa. Uno de ellos son los comentarios de Sloterdijk en torno a la relación de tránsito desde el eidos (aislado y frontal, pro-platonizante) a la producción de escenas (post-platónicas), en especial escenas "eminentes" y como "variaciones escénicas" ${ }^{30}$.

29. M. HeIDEgGer, Der Ursprung des Kunstwerkes, en Holzwege, GA 5 (Klostermann, Frankfurt, 1977), 19. Ed. cast. M. HeIDEgGER, El origen de la obra de arte, en Caminos de bosque (Alianza, Madrid, 1996) 27.

30. Debo remitir al lector interesado a P. SLOTERDIJK, Esferas I. Burbujas. Microesferología (Siruela, Madrid, 2014) 149-156. 
a) Más que un lugar de cosas / Cómo explicarle para qué éxtasis...

Por otra parte, y antes y más que esa relación entre eidos y escena, me ha servido como estímulo la lectura de El Rastro (1914), texto en el que Gómez de la Serna hace de extraordinario tutor/guía en sus paseos por el Rastro madrileño, en la medida en que sin cesar configura imaginativamente "escenas" a muchas de esas cosas usadas cuyo pasado, sin embargo, no podría (ni debería, incluso) meramente recordar — cabe un mundo fáctico- - Sólo quisiera mencionar aquí, a título formal, y sin entrar en detalles, el modo en que me figuro la imaginación de Gómez de la Serna enlazada, por ejemplo, a marcos sin cuadro, tinteros sin tinta, papel ni pluma, y espejos ${ }^{31}$ en los que sobreindeterminadamente tantas imágenes podrían ser enmarcadas, tantos textos escritos o tanto pudiera ser reflejado, respectivamente. También habría que destacar todas aquellas innumerables ocasiones en las que el narrador se refiere a los éxtasis que alcanzaría ante y con tal o cual objeto..., insospechados por su vendedor (por ejemplo, respecto a un posible puñal ${ }^{32}$ ). Todas las cosas del Rastro obran como impelentes de la imaginación en el sentido de suscitar la posibilidad de configurarles "escenas". Si bien desconoce su pasado, el narrador cuenta con los rasgos particularísimos de esto o aquello y, en especial, con los eide de las cosas impelentes: un paraguas, una taza, una percha, para lanzarlas (y protegerlas allí) en la configuración-deescenas. La imaginación no se pone al servicio de un mundo fáctico ni de un eidos, sino de variaciones escénicas donde guarecer una cuna, por ejemplo, no ya, obviamente, en su lugar de procedencia, como si se tratara de "restituirla" a su dueño, sino en el espacio libérrimo de destino de la imaginación del narrador - y del lector-. Una posibilidad, ésta, que avalaría la querencia del eidos por sus escenas posibles. Lejos de tan sólo "maniatar" las cosas, el eidos permitiría, en este sentido, por medio de la intencionalidad eidético-imaginativa, que

31. R. GómeZ DE LA SERna, El rastro, en Obras completas III (Galaxia Gutenberg, Barcelona, 1998) 177-178, 205-206 y 189-190 respectivamente. Cfr. C. MoRENO, Una suerte de calma hechizada. Praxis de extrañamiento y trascendencia poética (Paseando por el Rastro con Ramón Gómez de la Serna). Número monográfico: "Contrastes. Revista Internacional de Filosofía” XXI/3 (2016) 73-94.

32. R. GÓMEZ DE LA SERNA, El rastro cit., 161. 
pudiésemos acoger lo dado, como ejemplo, en horizontes figurativoescénicos de muy sobreindeterminada índole. En el fondo, la complacencia que experimentaba Gómez de la Serna en el Rastro dependía de la posibilidad de deshacerse-del-pasado fáctico de las cosas para que éstas ganasen una nueva dimensión en lo irreal (y a la postre, en un mundo de la vida no fácticamente sometido).

Pues bien, quisiera tomar como motivos dos ejemplos literarios que nos permitiesen aceptar la autoridad noético-noemática de un tutor fenomenológico en un entorno de neutralidad existencial, y ser a la vez co-creadores de la obra literaria (en sus espacios de indeterminación $\left.{ }^{33}\right)$, situándonos en una brecha de fenomenalidad de extraordinaria riqueza.

En los ejemplos que propondré, la nóesis imaginativa aprovecha recursos de diversa índole como medio para ir más allá, de modo que partiendo de un objeto, éste impele en desplazamientos o variaciones atencionales diversos ${ }^{34}$. He de insistir en que no se trata de que el objeto como polo de identidad retenga junto a sí o meramente remita-a, sino de que se convierta en objeto impelente. Si la fenomenología pudiera sentirse inquieta con esta sobreindeterminación en la impelencia, sólo lo sentiría si se comprometiera fuertemente con intencionalidades que exigieran mantenerse atadas al objeto en su potencial horizóntico-concreto, con su mero eidos, o con objetividades y situaciones objetivas que imperiosamente demandasen una posible verificación intersubjetiva (que quedaría dificultada en la medida en que la sobreindeterminación me incumbiese tan sólo a mí, lo que, sin embargo, no podría menoscabar la validez, e incluso validez extrema, de la impelencia). Pero si no es así, lejos de inquietarse, la fenomenología podría vislumbrar en esos objetos-impelentes una oportunidad sin parangón para la exploración del a priori de correlación, al que la fenomenología se debe sin cortapisas, restricciones ni complejos de ningún tipo (vaya incluso como crítica frente a cierto "conservadurismo" husserliano). En lo que sigue, respecto

33. R. IngARDEN, Das literarische Kunstwerk (Max Niemeyer Verlag, Tübingen, 1972) 261-270; W. IsER, El acto de leer. Teoría del efecto estético (Taurus, Madrid, 1987).

34. E. HusserL, Ideen I cit., 211 (ed. cast. 303). Habría que leer detenidamente el $\$ 92$. 
a los ejemplos que propondré, de nada valdría, para la honestidad fenomenológica, que se creyera que por aquí rondarían los peligros de un cierto psicologismo narcisista, en la medida en que (a ello se ha de "rendir" el fenomenólogo) son absolutamente operativos en, y expresivas de, nuestra vida personal imaginativamente sobremotivada.

\section{b) Todo sale de mi taza de té...}

Por ser muy conocida, no quisiera entretenerme demasiado con la "escena" de la magdalena en el volumen I de En busca del tiempo perdido. El narrador parte de un estado afectivo de melancolía tal que cuando degusta una magdalena mojada en té experimenta un estremecimiento al recaer su atención "en algo extraordinario" que ocurría en su interior. Un placer delicioso le invade hasta el punto de "aislarle", sin alcanzar noción alguna de lo que lo causaba. La alegría que experimenta entonces excedía al sabor "y no era de su misma naturaleza". La magdalena se convierte, pues, en hilo conductor de o puerta de entrada hacia "algo" que la desborda, por lo que el protagonista se apresta a indagar a qué propiamente le conducía, pues aunque apreciaba el exceso, no sabía exactamente a qué le transportaba. El objeto es tan intensamente impelente, que conduce a otra zona de experiencia que queda en principio muy indeterminada (pero más allá de la magdalena y su inmediato circunmundo). Tras varios intentos, llega a concluir que la verdad buscada estaba en sí mismo. Dice el narrador, entonces:

Dejo la taza y me vuelvo hacia mi alma. Ella es la que tiene que dar con la verdad. ¿Pero cómo? Grave incertidumbre ésta, cuando el alma se siente superada por sí misma, cuando ella, la que busca, es juntamente el país oscuro por donde ha de buscar, sin que le sirva para nada su bagaje. ¿Buscar? No sólo buscar, crear. Se encuentra ante una cosa que todavía no existe y a la que ella sola puede dar realidad, y entrarla en el campo de su visión.

Y otra vez me pregunto: ¿Cuál puede ser ese desconocido estado que no trae consigo ninguna prueba lógica, sino la eviden- 
cia de su felicidad, y de su realidad junto a la que se desvanecen todas las restantes realidades? ${ }^{35}$.

Agotado por el esfuerzo, experimenta cómo desde una zona muy hundida y lejana del pasado algo pugna por elevarse hasta su vivencia, intentando conectar eso que asciende con la actualidad del sabor, hasta que repentinamente recuerda con qué le conectaba el sabor de la magdalena, lo que le incita a una apología del poder pro(e)vocativo de la sobremención del objeto impelente. El recuerdo no sólo le trae a la memoria a su tía Leoncia los domingos por la mañana, cuando él era niño, sino la casa, y ésta, el pueblo, etc., y termina el narrador con un "todo sale de mi taza de té".

Entretanto, es importante destacar que todo este despliegue psico-fenomenológico transcurre imaginativamente en Proust como autor y, derivadamente, en sus lectores. La intencionalidad de horizonte motivada por el objeto impelente ha reafirmado y preservado a la magdalena como un medio de acceso inolvidable. Proust utiliza el poder impelente de un objeto impredecible hacia algo imprevisible. Las enseñanzas son múltiples, pero quizás la que más nos interesa destacar aquí es el modo en que la magdalena ha impelido a una dilatación que se presenta por medio de una suerte de concentración impelente pro(e)vocadora — que Proust ha imaginado-. Esta es, en el fondo, la gran enseñanza del pasaje: no simplemente un juego de meras remisiones, sino un juego de incitaciones que ha transcurrido en la imaginación literaria de nuestro ego experimental ficcional (el narrador/Proust).

\section{c) Quiero anotar... / Mi corazón espera también...}

El segundo ejemplo que quisiera proponer se adentra en la presencia intrapoemática de "un olmo seco". Se recordará —reconozco la injusticia que supone parafrasear el poema- que Machado describe el árbol en sus horizontes interno y externo como si él mismo estuviese allí, ante el olmo, para pasar seguidamente a presentificarlo

35. M. Proust, En busca del tiempo perdido (Alianza, Madrid, 1985) 61-62. 
(entreverlo) en sus posibles devenires, cuando el olmo dejase de ser tal para transformarse en un mero útil (campana, leña, yugo), o antes de que el viento lo tronchase o el río lo arrojase al mar... Pues bien, entre los "habitantes" del olmo no están sólo las arañas o las hormigas sino también, sobre todo, y en la más íntima verdad del poema (diríase que en su "nada"), el propio poeta, quien, como queriendo retener su presencia y al mismo tiempo proyectarse en ella, declara: "quiero anotar en mi cartera / la gracia de tu rama verdecida. / Mi corazón espera / también, hacia la luz y hacia la vida, / otro milagro de la primavera"36. Sin duda, ha sido "un olmo seco" el objeto impelente que ha suscitado la sobremención poética del mismo con la ayuda de una imaginación guiada por la tristeza y la esperanza del poeta. Pues bien, habría sido difícil que se hubiera preservado la presencia del olmo de no ser por esta sobremención que ha entre-visto en dicha presencia lo que le hacía ser él mismo, antes de dejar de ser... a partir del punctum ${ }^{37}$ de una pequeña rama verdecida ("¿quién iba a imaginarlo?”). Cuando el poeta le presta su atención sin duda está imaginando en favor del propio olmo, permitiéndole esa rama, vinculada insólito-imaginariamente a los afectos del poeta, preservar su presencia al tiempo que, milagrosamente, el olmo conduce al poeta completamente más allá del olmo mismo. A diferencia de la magdalena de Proust, que finalmente es un medio subsidiario que ayuda al narrador en su esfuerzo por recordar, la imaginación conduce a Machado a preservar al olmo mismo — que no está arraigado en ningún suelo, sino sencillamente presente en el seno del poema-.

\section{d) Ni siquiera tenemos que tener delante / \\ Nada más que, y sin embargo...}

Tal como se los concibe aquí, los objetos impelentes no son meramente remisionales en una intencionalidad de horizonte llamémosla

36. A. MACHADO, A un olmo seco (poema CXV), en Campos de Castilla, Obras completas I (Instituto Cervantes/RBA, Barcelona, 2005) 541-542.

37. R. Barthes, La cámara lúcida. Nota sobre la fotografía (Paidós, Barcelona, 1990) 63-67; C. Moreno, Tentativas sobre el rostro. Eidos y punctum, "ER. Revista de Filosofía” 19 (1995) 103-129. 
"básica", en la medida en que requieren un extra-ordinario horizonte de sobreindeterminación y la colaboración de una imaginación creadora. Quizás aporte cierta luz, a este respecto, pero en un sentido no diría que tanto contrario cuanto ambiguo, el pasaje de El origen de la obra de $a r t e^{38}$ en el que Heidegger prepara al lector para un adecuado abordaje de lo que significa la cosa-útil, del que se podría pensar en principio que brinda un interesante material para llegar a percatarnos de cómo la imaginación (encubierta como recuerdo) configura una escena (aunque Heidegger dijese, mejor, "descubra un mundo") a los objetos por medio de la cual éstos enlazan con la subjetividad, quedando personalizados. Así planteado, cualquier lector del texto heideggeriano podría alarmarse al considerar que nuestra lectura será injusta, pues precisamente Heidegger se esforzó mucho en desvincular de todo "quehacer subjetivo" el que el "unas botas" ("de campesino"), tal como se las brindaba Van Gogh, guardase relación alguna con una nóesis afectivo-imaginante. Pero justamente de esto se trata. Un asunto, ciertamente, algo turbio, de prevención filosófica, saturado de reparos, al que serían ajenos el novelista o el poeta, pero no el pensador Heidegger, que nos permitiría valorar en qué medida el mero horizonte de indeterminación, presionado por el de determinación ("rótulo", "título": "botas de campesino"), no nos permite comprender lo que se dilucida en un objeto impelente tal como aquí lo pensamos, que requiere no sólo de una mera imaginación, sino de la "euforia" de ésta.

No es fácil desbrozar el tema, bastante enrevesado. Para Heidegger, como es sabido, se trata de comprender el ser del útil. Para ello, se refiere a unas "botas de campesino" de las que dice de entrada que "ni siquiera necesitamos tener delante un ejemplar de ese tipo de útil", y ello porque "todo el mundo sabe cómo son". Ahora bien, añade, "puesto que pretendemos ofrecer una descripción directa, no estará de más procurar ofrecer una ilustración de las mismas. A tal fin bastará un ejemplo gráfico (eine bildliche Darstellung)" ${ }^{\prime 3}$. Decide, para ello, escoger un cuadro de

38. M. Heidegger, Der Ursprung des Kunstwerkes cit., 18-21 (ed. cast. 26-29). 39. Ibidem, 18 (ed. cast. 26). 
Van Gogh, del que reconoce que "pintó varias veces las mentadas botas de campesino". A renglón seguido se pregunta Heidegger "¿qué puede verse allí??", insistiendo en que "todo el mundo sabe en qué consiste un zapato" 40 Y un poco más adelante, deja claro que no se trata de representarse/imaginar.

Por el contrario, mientras sólo nos representemos (vergegenwärtigen) un par de botas en general, mientras nos limitemos a ver en el cuadro un simple par de zapatos vacíos y no utilizados, nunca llegaremos a saber lo que es de verdad el ser-utensilio del utensilio ${ }^{41}$.

Situación forzada ésta, sin duda, e incluso un tanto inverosímil, que quizás construye ad hoc el fantasma de una representación comprensivamente "ciega" en la medida en que, justamente por la intencionalidad de horizonte, cualquiera que sepa lo que son unas botas "ya recuerda/imagina" unos pies co-dados en ellas, obviamente.

En otro trabajo me ocupé de lo que dice Heidegger que "se ve", que no guarda relación con las botas mismas propiamente, sino con la vida/mundo del campesino ${ }^{42}$. En esta ocasión, sin embargo, requerirán nuestra atención las prevenciones de un Heidegger dispuesto a marginar la imaginación como modalidad por antonomasia de la Vergegenwärtigung, y ello porque si el propio Heidegger admitiera afirmar el rendimiento de una "intencionalidad de horizonte", la estructura de indeterminación de éste resultaría ser (debería ser) muy típica y familiar, lo que le permitiría imaginar poco y recordar mucho. El tema de la descripción de las botas en cuestión no tendría mayor importancia si no fuera porque Heidegger rechaza que la "descripción" se enlace a un quebacer subjetivo. Sin embargo, en verdad el asunto no gira en torno a la preeminencia de una mera representación (con Husserl ya comprobamos que en el análisis intencional no se trata de eso), sino en torno a la labor del recuerdo/

40. Ibidem.

41. Ibidem.

42. Cf. C. Moreno, De Mundo a Physis. Indagaciones heideggerianas (Fénix Editora, Sevilla, 2007) 49-72. 
imaginación cabe la intencionalidad de horizonte respecto a un objeto ambiguamente remisional- ¿impelente?, en este caso triple, porque entran en juego "unas botas" (de las que todo el mundo sabe lo son), "botas de campesino" (aquellas que dice Heidegger que son las que "se ven") y "Unas botas" (título del cuadro de Van Gogh).

Decía Heidegger que lo conseguido (su descripción) "lo hemos logrado única y exclusivamente plantándonos delante de la tela de Van Gogh. Ella es la que ha hablado". Y añadía, en posible referencia a lo que aquí hemos llamado "objeto impelente", que "esta proximidad a la obra nos ha llevado bruscamente a un lugar distinto del que ocupamos normalmente" y que

ha sido la obra de arte la que nos ha hecho saber lo que es de verdad un zapato. Si pretendiéramos que ha sido nuestra descripción, como quehacer subjetivo (subjektives Tun), la que ha pintado todo eso y luego lo ha introducido en la obra, estaríamos engañándonos a nosotros mismos de la peor de las maneras $^{43}$.

Propiamente, no ha sido la obra de arte la que nos ha hecho saber..., sino el propio quebacer subjetivo previo de Heidegger, del que depende la selección de esas botas... que le conducirán fácilmente al mundo del campesino (que tanto le atrae afectivamente). El "lugar distinto" al que, según dice Heidegger, "nos ha llevado bruscamente" la obra de arte, no es en verdad tan distinto ni lejano (así sería en el caso de un objeto impelente), sino que se trata de un lugar del que podríamos decir que Heidegger ya ha estado subjetivamente en él. Su osadía estriba en haber intentado reforzar su decisión diciendo que "estaríamos engañándonos a nosotros mismos de la peor manera" si creyésemos que ha sido un quehacer subjetivo el protagonista del develamiento del mundo del campesino. En verdad, si hubiera de admitirse que Heidegger no se ha "representado"/imaginado nada, sin embargo, habría que reconocer que se ha proyectado en algo en lo que recordar... (y recordarse). En unas lecciones de la misma época,

43. M. HeIdegGer, El origen de la obra de arte cit., 21 (ed. cast. 28). 
Heidegger se había referido a las botas, deslizándosele allí una transferencia interesante en la que vendría a ser el propio Heidegger el portador (imaginario) de las botas pintadas en el cuadro:

Aquel cuadro de Van Gogh: un par de zapatos rústicos, nada más. De hecho, la imagen no representa nada. Sin embargo, uno se encuentra enseguida a solas con lo que allí es, como si uno mismo (als ginge man selbst...), al caer la tarde otoñal, regresara cansado del campo a casa, con el pico en la mano y a la débil lumbre de las últimas brasas de la hojarasca de patata quemada. ¿Qué es aquí lo que es? ¿La tela? ¿Los trazos del pincel? ¿Las manchas de color? ${ }^{44}$.

Para Heidegger se trata de un ver que en cierto modo es un escuchar, y un acatar, aceptar, admitir ${ }^{45}$. En todo caso, como si el percibir implicase estar en la presencia más "hacia afuera", a diferencia del imaginar, más subjetivo y libre, y psicológicamente "interior", y a la vez menos sometido, menos acatador, dejando en libertad a las cosas para ofrecernos la posibilidad de configurarles escenas posibles.

Porque Heidegger se ha proyectado previamente, la posible sobreindeterminación del horizonte (potenciada por carecer las botas en el cuadro de Van Gogh de un entorno ${ }^{46}$, lo que nos facilitaría el imaginarle-escenas, al igual que favorecería esta imaginación el haber dicho simplemente, como dice Husserl del manzano en flor... "supongamos que miramos con agrado en un jardín un manzano en flor”...), decía que esa posible sobreindeterminación ha quedado debilitada, cuando no anulada, por la mera indeterminación cabe

44. M. HeIdegger, Einfuibrung in die Metaphysik, GA 40 (Klostermann, Frankfurt, $1983)$ 38. Ed. cast. M. HeIDEGGER, Introducción a la metafísica (Gedisa, Barcelona, 2001) 40-41.

45. Ibidem, 138, 139, 146 (ed. cast. 121, 122, 128-129 respectivamente).

46. M. HeIDegGer, Der Ursprung des Kunstwerkes cit., 18-19 (ed. cast. 26-27): "La tela de Van Gogh no nos permite ni siquiera afirmar cuál es el lugar en el que se encuentran los zapatos. En torno a las botas de labranza no se observa nada que pueda indicarnos el lugar al que pertenecen o su destino, sino un mero espacio indefinido. Ni siquiera aparece pegado a las botas algún resto de la tierra del campo o del camino de labor que pudiera darnos alguna pista acerca de su finalidad. Un par de botas de campesino y nada más. Y sin embargo...”. 
un horizonte de familiaridad previo, que Heidegger "llena" fácilmente con un "recordar" que le evita creer que, encubierto por ese recordar, pudiera haber un imaginar, y eludir, además, los posibles rendimientos de una atención eidética a las botas que podría concretarse en variaciones escénicas posibles y potencialmente impredecibles (como ocurre con la magdalena y el olmo) y al que le habría bastado aquel "todos sabemos lo que son" unas botas (y además, "de campesino"). Al elegir tales botas en tal cuadro de Van Gogh, Heidegger apuesta por un ver que puede identificar con un recordar/ acatar, impidiendo dar "alas" a "la loca de la casa" (imaginación). De haber sostenido que imaginaba el "mundo del campesino" como horizonte de las botas, éste habría quedado vinculado a un quehacer subjetivo creativo y casi como dejado en suspenso y desarraigada y desapropiada la verdad del ser, a expensas de una contingencia, en la medida en que las botas por sí mismas, y más específicamente, en tanto se presentan en el cuadro sin un horizonte externo, podrían ser de un campesino, ciertamente, pero también de un urbanita o del propio Van Gogh ${ }^{47}$, etc.

De entrada, así pues, diríase que Heidegger elige un objeto que es meramente remisional, pero no impelente. No se trata de decir que Heidegger ha imaginado, pues no es tal su intencionalidad —si apostamos por creerle-, pero sí se ha reconocer que la elección de esas botas le dejan "ver"-recordar o recordar-"ver" el mundo del campesino conectado (quizás subconscientemente - habría que dejarlo indeciso-) con un quebacer subjetivo-afectivo (aunque lo desdeñase como anecdótico).

Las botas que pinta Van Gogh podrían haber sido para Heidegger un objeto impelente si previamente no hubiese decidido elegirlas para recordar en torno a lo que "se deja ver" en ellas, pero no lo son, pues su horizonte de indeterminación no llega a ser de sobreindeterminación, de modo que ésta alentase a la imaginación creadora - y a la conciencia potenciada (vid. nuestra nota 25)—.

47. M. SCHAPIRO, La naturaleza muerta como objeto personal: unas notas sobre Heidegger y Van Gogh y Unas cuantas notas más sobre Heidegger y Van Gogh, en Estilo, artista y sociedad (Tecnos, Madrid, 1999) 147-162. 
De este modo, Heidegger remite a las botas a un horizonte de procedencia / arraigo / pasado que debe ser recordado / acatado, no hacia un futuro (vía imaginación / eidos). Además, para Heidegger, en todo caso se trataría de recordar no en dirección a la vida del testigo (Proust, Machado), sino en dirección al mundo del campesino. Como reconoció Derrida, tanto Heidegger como Schapiro se supeditan a la exigencia de "restituir" lo que se ve (unas botas) a un sujeto, a un dueño, desviándose de la imagen como tal, en su neutralidad. Las botas, que en principio pudieran habernos parecido un objeto impelente, en verdad no lo son precisamente porque no están al cuidado de la imaginación cabe un horizonte de sobreindeterminación (que un surrealista intensificaría más aún, desde luego). Para eso tendría que ser cortado el vínculo (que previamente Heidegger ya ha decidido que es necesario) entre botas y mundo del campesino... La magdalena de Proust impele a un pasado no recordado previamente (y en ello estriba el esfuerzo que narra Proust); la magdalena se le presenta ex novo como impeliéndole a algo que el narrador no sabe qué es; por así decirlo, de entrada la magdalena carece de "pasado" y a esta carencia se conecta su fuerza impelente. Respecto al olmo de Machado, nada absolutamente en él podría remitir desde su presencia al corazón del poeta. Los objetos impelentes "magdalena..." y "olmo..." son impelentes para el novelista y el poeta hacia el encuentro de sí mismos.

En presencia de las botas, de esas botas -y no otras posibles, que habrían surgido en un (imaginémoslo) husserliano "supongamos que vemos con agrado unas botas”, éstas parece que sólo podrían tener una verdad, y que esta verdad no habría, sino que ha de ser fáctica (mundo del campesino) ${ }^{48}$ y no debe ser imaginada, sino "vista".

48. En lo que quizás se aprecia la deuda heideggeriana con la metodología de la hermenéutica de la facticidad, a la altura de 1923, cuando para oponerse a lo que sería la incorrecta descripción fenomenológica practicada por Husserl, Heidegger pone ejemplos relativos a una mesa y unos esquíes de los que él fue propietario, y cuya verdad conecta con sus recuerdos. M. HeIDEgGER, Ontologie. Hermeneutik der Faktizität, GA 68 (Klostermann, Frankfurt, 1988) 90-91. Ed. cast. M. HEIDEGGER, Ontología. Hermenéutica de la facticidad (Alianza Editorial, Madrid, 1999) 115-116. En el caso de las botas, sin embargo, no son suyas, aunque, como hemos dicho, tiene que "considerarlas como suyas" para poder fingir que no imagina, sino que "recuerda". 
Para Heidegger no se trataba de "configurar escenas" imaginativamente, ni de un mero descubrimiento del ser de las botas en torno a unos pies y un caminar... (incluso sin camino, para colmo de exasperación de la querencia de facticidad), sino de acordarles (recordándolo) un mundo previamente dado y que ya actúa precomprensivamente en su elección. Todo se ha tornado no ya visible, sino previsible, y es difícil asentir a que las botas nos hayan llevado muy lejos... (como en aquel "todo ha salido de mi taza de té" de Proust o en el olmo de Machado). Sin embargo, el objeto impelente no es de entrada "rastreable" ni requiere de una policía que preserve su "verdad" como una verdad que pudiera ser demostrada.

$$
* * *
$$

Si bien la imaginación encuentra uno de sus terrenos propicios en la estructura de indeterminación de la intencionalidad de horizonte, en verdad llega a ser creativa cuando la mera indeterminación se vincula con una sobreindeterminación en la que pudiese encontrar verdadera soltura o desahogo aquella indeterminación. Ocurre como con las variaciones eidéticas, que sólo son realmente valiosas y confirman la amplitud y profundidad del eidos cuando en su recorrido llegamos a explorar las zonas más alejadas de los apegos que dificultarían una intuición eidética realmente pura, libre de "lazos secretos"49 a nuestro mundo próximo, familiar o rutinario. El camino heideggeriano es, claramente, el del compromiso hermenéutico con la facticidad.

Por cierto, en El origen de la obra de arte Heidegger nos había ofrecido un adecuado ejemplo de la riqueza de un imaginar sin una decisión previa acerca del mundo fáctico en que forzosamente hubiera de acontecer singularmente lo imaginado en cada caso. Me refiero al ejemplo que nos brinda no propiamente de variaciones eidético-imaginativas del eidos sonido-ruido, sino de variaciones a punto de ser "escénicas" del eidos sonido a fin de esclarecer la diversidad de nuestros compromisos fácticos. Heidegger no parte del pre-comprender en cada caso... sino, como pensador, de la pre-

49. E. HusserL, Erfahrung und Urteil cit., 424 (ed. cast. 388). 
sentación —escueta pero suficiente- de figuraciones imaginativas en torno al sonido que podrían ser convocadas no sólo (como Heidegger preferiría, sin duda) para criticar que haya algo así como sensaciones "puras" no hermenéuticamente mediadas, sino también para recordarnos la plétora del eidos sonido y su fuerza-de-donación y sobremención. En efecto, decía Heidegger, el sonido puede ser de

cómo silba el vendaval en el tubo de la chimenea, el vuelo del avión trimotor, el Mercedes que pasa y que distinguimos inmediatamente del Adler. Las cosas están mucho más próximas de nosotros que cualquier sensación. En nuestra casa oímos el ruido de un portazo pero nunca meras sensaciones acústicas o puros ruidos. Para oír un ruido puro tenemos que hacer oídos sordos a las cosas, apartar de ellas nuestro oído, es decir, escuchar de manera abstracta ${ }^{50}$.

Tal vez Heidegger supo percatarse también de la proximidad (demasiado humana, se dirá) de lo que imaginamos, y no sólo de lo que en cada caso percibimos y comprendemos hermenéuticamente, pero la rechazó como un quehacer subjetivo o como un puro contemplar eidético o eidetizante desarraigado. De aquí que despreciase con un "escuchar de manera abstracta" eso del "ruido puro", para lo que hay que hacer "oídos sordos a las cosas", lo que nos haría considerar que aún son las cosas y nuestros compromisos fácticos los "dueños" del "sonido", a los que debemos restituirlo, en los que tenemos que arraigarlo. Y, sin embargo, ¿acaso la "suma de sonidos y ruidos" no es siempre más y más abiertamente no ya cuando es simplemente despreciable como el rótulo fácil de una "abstracción", sino cuando lo que se mienta en "suma de sonidos y ruidos" es imaginado-concretado, pero a la vez dejado en libertad-en-variaciones-escénicas en la euforia de la imaginación, más allá de la remisión a un mundo consumado e irrevocable (sonido de un Adler o un Mercedes, pero sólo de uno u otro)? Ahora comprendemos mejor que el recorrido eidético, tal como lo pensaba Husserl, debe ser de variaciones, no de

50. M. HeIDEgGER, El origen de la obra de arte cit., 10-11 (ed. cast. 19). 
alteraciones de lo dado-imaginado ${ }^{51}$, variaciones que, todas, en toda su diversidad, deberían poder convivir o coexistir "en" el eidos $-\mathrm{y}$, sobre todo, con las más alejadas de nuestros prejuicios, rutinas y familiaridades-.

El "artista" lo sabe, y quizás por eso busca distanciarse de una verdad que hubiese simplemente, o sobre todo, que constatar (lo que vemos) o recordar. Y un filósofo, ciertamente, cabe imaginar que debiera no olvidarlo, no sólo porque hubiese de recordar el vínculo con el aparecer que incumbe al artista, sino también porque temiese el empobrecimiento - a cambio de arraigo, consistencia y facticidad-que llevaría consigo la expulsión de la imaginación fuera del Pensar.

En tal sentido, los objetos impelentes supondrían un estímulo impagable para la vida de la conciencia, en todas sus posibilidades, por el desafío que suponen para una fenomenología que en verdad debiera aventurarse en tierras incultas (incluso selvas) sin caminos, donde la verdad de unas botas en el fondo último de su verdad no apelaría meramente a un mundo fáctico-concreto, sino justamente, en honor a ese "sin caminos", sobre todo a la posibilidad misma de bacer camino al andar.

51. E. HusserL, Erfahrung und Urteil cit., 410-412 (ed. cast. 384-385). 